\title{
A new BDA structure
}

The democratic
process is as it always
has been, but the
mechanism of making
decisions as to how
policy is to be
implemented will be
much faster and
therefore more
effective.

Mike Grace m.grace.bdj@bda-dentistry.org.uk

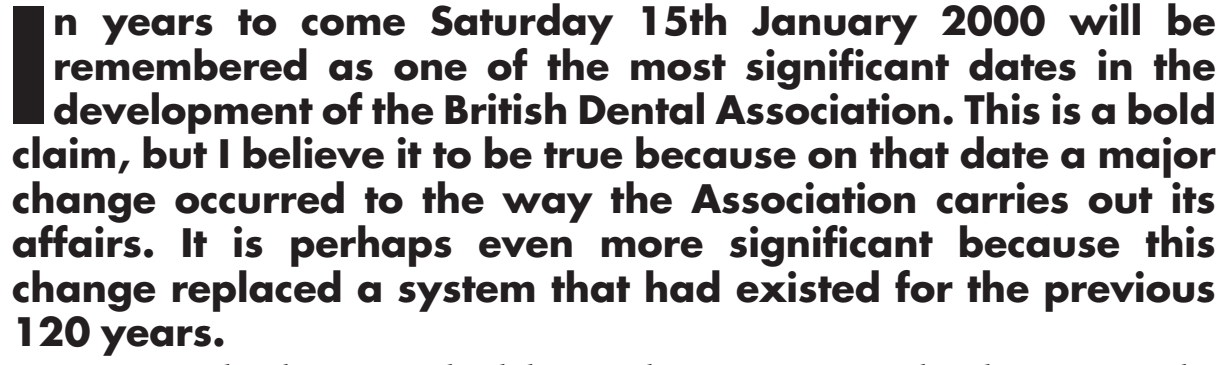

In essence the change involved the way the Association makes decisions. In the past, in order to represent the views and wishes of its members in a democratic and appropriate way, the BDA membership appointed representatives from the various branches throughout the UK to form the Representative Board, affectionately referred to as the 'Rep Board'. This Board consisted of approximately 70 people who were the directors of the Association and who met three times a year to make decisions. The Board then elected BDA Council from within its own members, a smaller committee of approximately 20 individuals who carried out the day-to-day business based on the decisions taken by the 'Rep Board'.

This system served the Association well, but as the tempo of life began to accelerate it was beginning to show its deficiencies, especially in regard to rapid responses to the changing environment. For this reason a complex and lengthy process of re-evaluation started several years ago to replace the old system with one that would allow the elected officers and BDA staff to work more effectively.

This process of evaluation took time because it was essential to retain the important and necessary value of democracy that were enshrined in the old system. The result of this evaluation was duly completed, voted on, and finally put into place for the new triennium that started this January.

The major change is one that seems sensible today. While major policy and strategic direction remains the responsibility of a large group of representatives as in the past, the actual management of those decisions will now fall to a much smaller group, elected as before. Put simply, the Representative Body (previously the 'Rep Board') decides what is to be done, while the Executive Board (previously BDA Council) decides how. Thus the democratic process is as it always has been, but the mechanism of making decisions as to how policy is to be implemented will be much faster and therefore more effective.

The details of the new structure for the Association is published in BDA News for members to read in full, and need not concern us here. What is so encouraging is that much of the work carried out by the Association should now fall to small, task-orientated working groups rather than cumbersome, large committees. It is hard to see how anyone could criticise this approach as long as it is carried out as intended. The checks are in place to ensure the democratic process is adhered to, and the end result will be more open and transparent than before.

The only danger I can see to the new approach is the danger of reversion to 'old habits'. Some people who have always been used to working in large committees may require training and help, or perhaps simply excellent chairmanship, to ensure they do not lapse back into old ways. The success of the new approach will rely on the capability of the leaders of the newly elected Body and Board, and the training of all participants. This has been addressed in a programme of management development for all involved, so things look even more encouraging.

A final note, more in the spirit of good humour than in serious concern, is the difficulty of nomenclature. The old 'Board' is now a 'Body' and the old 'Council' is now a 'Board'. I am sure this will initially lead to some confusion, but I am quite surprised how quickly even I am beginning to replace the old terms with the new. 